\title{
Quadruple therapy for symptomatic spontaneous duodenal ulcer disease
}

\author{
M C Bateson
}

\begin{abstract}
Aim-To investigate Helicobacter pylori eradication in duodenal ulcer patients with a new regimen, lansoprazole $30 \mathrm{mg}$ daily for one or four weeks plus twice daily tetracycline $500 \mathrm{mg}$, clarithromycin 250 $\mathrm{mg}$, and metronidazole $400 \mathrm{mg}$.

Background-Spontaneous duodenal ulcer is regularly associated with $\mathrm{H}$ pylori, and permanent cure follows eradication of this bacterium. Numerous treatments have been proposed and none is ideal, possibly because of primary or acquired antibiotic resistance. Quadruple regimens with proton pump inhibitor therapy and three antibiotics offer promise as the most effective therapy.

Methods-From November 1995 all patients with spontaneous duodenal ulcer were offered quadruple therapy. A month after completion a carbon 14 urea breath test (UBT) was performed. Sensitivity of $H$ pylori to the antibiotics used was tested in 1992-3, 1996, and 1999.

Results-A total of 331 patients were treated; 313 attended for a UBT, of which 299 were negative $(95.5 \%)$. Of those patients who had an endoscopy with positive urease test immediately before treatment, 95/101 $(94.0 \%)$ on lansoprazole for one week and $116 / 121(95.8 \%)$ on lansoprazole for four weeks had a negative UBT. $H$ pylori antibiotic sensitivity did not change.

Conclusion-This regimen produced some of the best results yet seen and may be generally recommended as first line therapy.
\end{abstract}

(Postgrad Med F 2001;77:447-450)

Keywords: Helicobacter pylori; duodenal ulcer

The discovery that spontaneous duodenal ulcer is regularly associated with Helicobacter pylori infection has led to a complete change in management. ${ }^{1}$ When the organism is eradicated the ulcers heal and do not return unless ulcerogenic drugs are used. ${ }^{2}$

However, there are some problems in treatment. Many ulcers are induced by aspirin and non-steroidal anti-inflammatory drug therapy, and occasionally ulcers are caused by severe stress, hypercalcaemia, or hypergastrinaemia. These must be excluded as factors if good results are to be obtained with anti- $H$ pylori regimens. Investigations for active $H$ pylori infection such as direct urease testing and histology on gastric biopsy specimens, and carbon 13 and carbon 14 urea breath tests (UBTs), may be temporarily negative in patients who are taking or who have recently taken antibiotics, bismuth, and acid suppressing drugs. ${ }^{3}{ }^{4}$ Though $H$ pylori is very sensitive to a variety of antibiotics in the laboratory they do not always help patients. Amoxicillin alone is ineffective in treatment, though $\mathrm{H}$ pylori is universally sensitive to this agent. Combinations of drugs are required with problems of tolerability, variable efficacy, and alleged or actual penicillin sensitivity. Whether laboratory sensitivity testing is useful in guiding treatment of individual patients is contentious, particularly when multiple antibiotics are used. ${ }^{5-15}$

Often early claims of high effectiveness of treatment schemes cannot be confirmed later. Bismuth, tetracycline, and metronidazole for two weeks was the standard therapy initially, ${ }^{11}{ }^{16}$ but is now considered obsolete because of low efficacy and poor tolerability by patients. ${ }^{15}$ There was a need for better treatment and it was decided to test the use of a novel combination of drugs in routine patient management.

Important questions were whether the use of three antibiotics conferred additional benefit over two, whether prolonged lansoprazole therapy was better than just one week, and whether double dose lansoprazole was necessary.

Subjects and methods

Bishop Auckland General Hospital serves a mixed rural and urban population of 150000 in north east England, of whom less than $0.5 \%$ are from ethnic minorities. There has been an open access endoscopy service for 10 years, and currently 2300 patients are gastroscoped each year. About 70 adult patients with spontaneous duodenal ulcers are identified annually under the care of the single handed gastroenterologist. From January 1992 all patients with spontaneous duodenal ulcer were offered eradication therapy, and the results were assessed by carbon 14 UBT. $^{16}{ }^{17}$ From November 1995 all patients were considered for the quadruple therapy described.

The diagnosis of duodenal ulcer was established by gastroscopy or unequivocal barium meal, and all patients had symptoms consistent with this diagnosis. Endoscopic antral gastritis, gastric antral erosions, duodenitis, and duodenal erosions were often seen in the study group. 


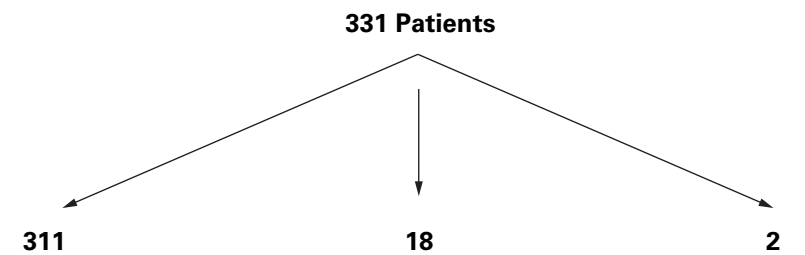

Treated + UBT at 1-2 months

Treated, did not attend for UBT

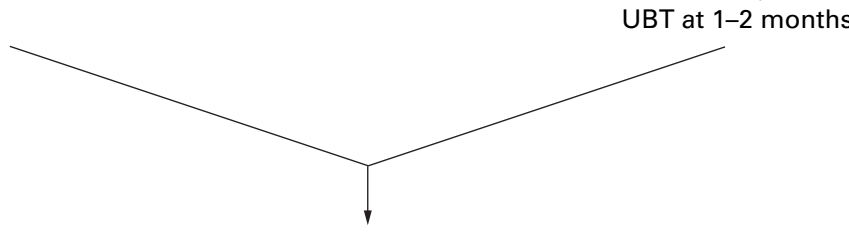

$299 / 313=95.5 \%$

Negative UBT

Figure 1 Quadruple therapy for spontaneous duodenal ulcer, November 1995 to March 2000.

Table 1 Results of antibiotic sensitivity testing, \% sensitive by $E$ test

\begin{tabular}{lllll}
\hline & Amoxicillin & Tetracycline & Clarithromyin & Metronidazole \\
\hline $1992-96$ & 100 & 99 & 98 & $98(81 \%$ without anaerobic phase $)$ \\
1999 & 100 & 100 & 97 & 98 \\
\hline
\end{tabular}

However, the presence of oesophagitis, gastric ulcer, or oesophageal or gastric cancer excluded patients.

Either no specific anti- $H$ pylori therapy had been given, or it had been shown to have failed by subsequent positive UBT (eight patients). No patients had been taking aspirin or non-steroidal anti-inflammatory drugs before diagnosis. None of the patients were pregnant and women in the childbearing years were advised to avoid pregnancy by taking appropriate precautions. Where patients had a gastroscopy performed immediately before treatment a direct urease test was taken and they were analysed as a specific subgroup. ${ }^{18}$

Usually treatment was prescribed from the hospital but if primary care doctors prescribed they were asked to confirm this in writing in every case. No patients reported previous intolerance to any of the antibiotics used, but one stated that vaginal thrush regularly complicated any antibiotic use, and she was offered additional fluconazole treatment as prophylaxis. Two patients reported diarrhoea after previous lansoprazole therapy. Pantoprozole 40 mg daily for one week was substituted and both had successful treatment.

All patients were treated with lansoprazole once daily and were given one week's treatment with twice daily tetracycline $500 \mathrm{mg}$, clarithromycin $250 \mathrm{mg}$, and metronidazole $400 \mathrm{mg}$.

The first 127 were given lansoprazole $30 \mathrm{mg}$ daily concurrently with antibiotic treatment and then for a further three weeks (LTCM2 group). The next 137 were given lansoprazole $30 \mathrm{mg}$ daily only for the week of antibiotic treatment $(4 \times 1$ group). All subsequent patients were given lansoprazole for a month as initially. The patients were evenly matched on the two treatments. In the LTCM2 group the median age was 57 (range 17-90) with $30 \%$ women. In the $4 \times 1$ group the median age was 58 (22-87) with $26.2 \%$ women. Between 1-2 months after completion of all treatment patients were asked to attend fasting for a carbon 14 UBT. An oral dose of $0.2 \mathrm{MBq}$ carbon 14 urea was given in a small quantity of water without any test meal. Breath samples were collected in a trapping agent at 20 and $30 \mathrm{~min}-$ utes and the highest count was taken as the result, with a cut off point of $0.75 \%$ dose $/ \mathrm{mmol}$ carbon dioxide $\times$ body weight.

\section{Results}

The results are shown in fig 1. A total of 331 patients with spontaneous symptomatic duodenal ulcer were prescribed quadruple therapy; 222 actually had a gastroscopy with positive direct urease test immediately before entry into treatment. Eighteen patients did not attend for the UBT, 13 in the LTCM2 group and five in the $4 \times 1$ group. One of these was known to have stopped treatment at one day because of vomiting, but the others are not known to have defaulted from therapy and none sought further medical attention for dyspepsia. Altogether 313 attended for the UBT as requested and 299 had a negative test $(95.5 \%)$.

In the patients who had a gastroscopy with positive urease test immediately before treatment, the UBT was negative in 95/101 $(94.0 \%)$ who had taken lansoprazole for one week $(4 \times 1$ group) and in $116 / 121(95.8 \%)$ who had taken lansoprazole for four weeks (LTCM2 group). Eight patients had taken other anti-H pylori regimens before which had failed with positive UBTs afterwards, three on two occasions. Three out of these eight again had a positive UBT after quadruple therapy.

Serious side effects were seen in five patients in the LTCM2 group: two had diarrhoea, two had vomiting which stopped treatment at one day in one patient, and one had oral thrush. Only one patient in the $4 \times 1$ group had a serious side effect. She was on treatment with carbamazepine, ethosuximide, and lamotrigine for epilepsy and had a fit after completing the week's antibiotic treatment. Subsequently her UBT was negative.

Antibiotic sensitivity was tested in 94 patients in 1992-3 and 1996 by E test, and in 72 patients in 1999 by E test, ${ }^{14}{ }^{19}{ }^{20}$ and agar gel dilution. ${ }^{20}$ Results of these two techniques were similar. Sensitivity was defined as a minimum inhibitory concentration (MIC) $<8 \mathrm{mg} / 1$ (or $<4$ $\mathrm{mg} / \mathrm{dl}$ for clarithromycin), but modal MIC values were $<0.016$ to $0.032 \mathrm{mg} / 1$ (table 1 ).

\section{Discussion}

This quadruple therapy gave an overall eradication rate of $95.5 \%$ (per protocol) in unselected patients with symptomatic spontaneous duodenal ulcers in routine clinical practice. There was no difference between UBT results in patients on lansoprazole given for one week or four weeks, though it is likely that the early healing rate will be higher where lansoprazole is given for a longer period. ${ }^{21-23}$ This may be preferred because of the theoretical attraction of quicker ulcer healing, and the fact that even 
Table 2 Results of previous anti-H pylori regimens in spontaneous duodenal ulcer

\begin{tabular}{lllc}
\hline Drugs & $\begin{array}{l}\text { Duration } \\
\text { (weeks) }\end{array}$ & No treated & UBT negative \\
\hline $\begin{array}{l}\text { Bismuth } \\
\text { Tetracycline }\end{array}$ & 2 & 101 & $83(82 \%)$ \\
Metronidazole & 2 & & \\
$\begin{array}{l}\text { Lansoprazole } \\
\text { Amoxycillin, metronidazole }\end{array}$ & 2 & 104 & $92(88 \%)$ \\
$\begin{array}{l}\text { Lansoprazole } \\
\text { Clarithromycin, tinidazole }\end{array}$ & 1 & & $104(93 \%)$ \\
$\begin{array}{l}\text { Lansoprazole } \\
\text { Tetracycline 250 mg twice a day }\end{array}$ & 4 & 112 & $69(93 \%)$ \\
Clarithromycin, metronidazole & 1 & 74 & \\
\hline
\end{tabular}

when eradication therapy failed patients had been given at least one short term therapy of proved efficacy. However, it is likely that the long term result will be the same for both LTCM 2 and $4 \times 1$ groups.

This large audit produced results significantly better $(\mathrm{p}<0.001)$ than our previous experience with triple therapies, and with a similar quadruple therapy regimen but using tetracycline only $250 \mathrm{mg}$ twice daily (table 2 ). ${ }^{24}$

The carbon 14 UBT service has been used routinely after duodenal ulcer treatment since January 1992. It is provided by the medical physics department at Dryburn Hospital, 15 miles from Bishop Auckland General Hospital, and patients must attend in person. The travelling involved may explain the $5.4 \%$ failure rate in attendance for the UBT. It seems likely that most of these patients were successfully treated and symptomatically cured, and did not wish to spend more time proving the point. All of the first 66 patients had negative UBTs, emphasising the need for a larger series to provide a true picture of overall effectiveness.

The standard dose of lansoprazole $30 \mathrm{mg}$ daily was used because it gives optimal acid suppression, equivalent to $40 \mathrm{mg}$ of omeprazole or $40 \mathrm{mg}$ of pantoprazole. Though others have used double dose lansoprazole in their series this does not seem logical and would not have been likely to improve our results. ${ }^{23}{ }^{25}$ The cost of treatment is hard to calculate exactly. Hospital dispensary costs are about $f_{16}-23$, with clarithromycin the most expensive item. General practitioner and outside pharmacy dispensary costs are greater at about $£ 22-44$, with lansoprazole the major item if treatment is used for a month.

It is useful to assess treatment success by the UBT, which is how we discovered alternative regimens were not as good as expected. Carbon 13 UBT kits are now prescribable $(£ 21)$ and will give equivalent results to the carbon 14 UBT. ${ }^{26}$ Consumables for carbon 14 UBTs are $£ 4$ but this usually requires attendance at a medical physics department, with an additional cost in technician time.

Because these were patients attending for investigation and treatment they were managed in a conventional manner and, therefore, a UBT was not routinely arranged before treatment nor check gastroscopy afterwards as this is not standard practice in duodenal ulcer disease.
Since all patients had spontaneous duodenal ulcers it may be inferred that they were infected with $H$ pylori before treatment. ${ }^{1}$ This is strongly supported by the identical results overall to the subgroup where a positive urease test was obtained immediately before therapy. Conventional wisdom is that absence of $\mathrm{H}$ pylori obviates the risk of spontaneous duodenal ulcer in the future, so that a negative UBT is a useful surrogate for actual or eventual duodenal ulcer healing. ${ }^{17}$ The risk of reinfection is very low, around $1 \%$ annually, but these patients are not immune from iatrogenic ulceration.

The usefulness of laboratory sensitivity testing is problematical. It clearly showed that the local $H$ pylori population remained sensitive to antimicrobials in the short term. However, the effect of wide use of antibiotics in duodenal ulcer on other organisms is not yet known. It has been proposed that nitroimidazole resistance as measured by microaerophilic testing predicts outcome for less effective triple regimens. ${ }^{1915}$ This does not seem to be the case with quadruple therapy. ${ }^{10-12}$ Though we did show an apparent 19\% metronidazole resistance when $H$ pylori was cultured without a 24 hour anaerobic phase, this largely disappeared when this was incorporated. The relevance of partial metronidazole resistance is dubious in clinical practice. ${ }^{5614}$ The lack of increase in antibiotic resistance in this series mirrors that seen elsewhere, though others still feel this to be a problem. ${ }^{13}$

This survey of actual real life management of duodenal ulcers has been able to validate a new simple quadruple regimen which almost all adults can take easily. The success rate is equal to the best of the many other published series and it can be recommended for general use as standard first line treatment.

Strong support for this study was given by Professor Brian Diffey and Dr Alison Mackie of the local medical physics service, Mr Gary Winn and Dr Fareed Ahmad of the Bishop Auckland microbiology laboratory, and the staff of the Bishop Auckland Gastroenterology Unit.

1 de Boer WA, Tytgat GNJ. Treatment of Helicobacter pylori infection. BMF 2000;320:31-4.

2 Logan RPH, Bardhan KD, Celestin LR, et al. Eradication of Helicobacter pylori and prevention of recurrence of duodenal ulcer: a randomized double-blind multi-centre trial of omeprazole with or without clarithromycin. Aliment Pharmacol Ther 1995;9:417-23.

3 Dickey, W, Kenny BD, McConnell JB. Effect of proton pump inhibitors on the detection of Helicobacter pylori in gastric biopsies. Aliment Pharmacol Ther 1996;10:289-93.

4 Savarino V, Bisso G, Pivari M, et al. Effect of gastric acid suppression on 13 C-urea breath test: comparison of ranitidine with omeprazole. Aliment Pharmacol Ther 2000;14: dine with

5 Walt RP. Metronidazole-resistant $\mathrm{H}$ pylori-of questionable clinical importance. Lancet 1996;24:489-90.

6 van Zwet AA, Thijs JC, de Graaf B. Explanations for high rates of eradication with triple therapy using metronidazole in patients harboring metronidazole-resistant Helicobacter pylori strains. Antimicrob Agents Chemother 1995;39:250-2. 7 Breuer T, Kim JG, Gurer IE, et al. Successful low dose amoxycillin, metronidazole and omeprazole combination therapy in a population with a high frequency of metronidazole-resistant Helicobacter pylori. Aliment Pharmacol Ther 1997;11:523-7.

8 Strom M, Sorbert M, Jonsson KA. Immediate repeat course of amoxycillin, metronidazole and omeprazole to eradicate Helicobacter pylori. Aliment Pharmacol Ther 1997;11:311-16.

9 Houben MHMG, van de Beek D, Henson EF, et al. A systematic review of Helicobacter pylori eradication therapythe impact of antimicrobial resistance on eradication rates. Aliment Pharmacol Ther 1999;13:1047-55. 
10 Borody TJ, Andrews P, Fracchia G, et al. Omeprazole Borody TJ, Andrews $\mathrm{P}$, Fracchia $\mathrm{G}$, et al. Omeprazole enhances efficacy of triple therapy
bacter pylori. Gut 1995;37:477-81.

11 Okada M, Nishimura H, Kawashima M, et al. A new quadruple therapy for Helicobacter pylori: influence of resistant strains on treatment outcome. Aliment Pharmacol Ther 1999;13:769-74.

12 Hosking SW, Ling TKW, Yung MY, et al. Randomised controlled trial of short term treatment to eradicate Helicobacter pylori in patients with duodenal ulcer. $B M F$ 1992;305:502-4.

13 Alarcon T, Domingo D, Lopez-Brae M. Antibiotic resistance problems with Helicobacter pylori. International fournal of Antimicrobial Agents 1999;12:19-26.

14 Bateson MC, Winn G, Ahmad F. Sensitivity of Helicobacter pylori to metronidazole. Eur F Cancer Prev 1997;6:300-2.

15 Bell GD, Powell K, Burridge SM, et al. Experience with "triple" anti-Helicobacter pylori eradication therapy: side "triple" anti-Helicobacter pylori eradication therapy: side terial isolate for metronidazole resistance. Aliment Pharmaterial isolate for metronida

16 Goddard AF, Logan PH. Urea breath tests for detecting Helicobacter pylori. Aliment Pharmacol Ther 1997;11:641-9. 7 McColl KEL, El-Nujumi Helicobacter pylori breath test: a surrogate marker for peptic ulcer disease in dyspeptic patients. Gut 1997;40:302-6.

18 Bateson MC, Baborie A, Bakir A, et al. "One-minute" urease testing for Helicobacter pylori. Gut 1995;37:A30.
19 Cederbrant G, Kahlmeter G, Ljungh A. The E test for antimicrobial susceptibility testing of Helicobacter pylori. $\mathcal{F}$ 1993;31:65-71.

20 Hirschl AM, Hirschl MM, Rotter ML. Comparison of three methods for the determination of sensitivity of Helicobacter pylori to metronidazole. F Antimicrob Chemother 1993;32: $45-9$

21 McFarland RJ, Bateson MC, Green JRB, et al. Omeprazole provides quicker symptom relief and duodenal ulcer healing than ranitidine. Gastroenterology 1990;98:278-83.

22 Bazzoli F, Gullini S, Zagari RM, et al. Effect of omeprazole and clarithromycin plus tinidazole on the eradication of Helicobacter pylori and the recurrence of duodenal ulcer. Gut 1995;37:A241.

23 Harris AW and the Lanzoprazole Helicobacter Study Group. Incidence of duodenal ulcer healing after 1 week of proton pump inhibitory triple therapy for eradication of Helicobacter pylori. Aliment Pharmacol Ther 1998;12:7415 .

24 Bateson MC, Diffey BL. Improving management of duodenal ulcer disease. Postgrad Med f 1997;73:717-19.

25 Sieg A, Sellinger M, Schlauch D, et al. Short-term triple Sieg A, Sellinger M, Schlauch D, et al. Short-term triple
therapy with lansoprazole $30 \mathrm{mg}$ or $60 \mathrm{mg}$, amoxycillin and therapy with lansoprazole $30 \mathrm{mg}$ or $60 \mathrm{mg}$, amoxycillin and Pharmacol Ther 1999;1:865-8.

26 Ali A, Vaira D, Stanghellini V, et al. Comparison between $13 \mathrm{C}$ vs $14 \mathrm{C}$ urea breath test for Helicobacter pylori diagnosis. Ital f Gastroenterol Hepatol 1998;30:A91.

\section{Narrative Based Medicine, An Interdisciplinary Conference}

Research, Narrative, and Practice

\section{A two day conference-Monday 3rd and Tuesday 4th September 2001}

\section{Homerton College, Cambridge, UK}

\section{BMf Publishing Group}

For full details contact: BMA/BMJ Conference Unit, Tavistock Square, London, WC1H 9JP Tel: +44 (0)207383 6819; fax: +44 (0)207383 6663; email: clyders@bma.org.uk.

www.quality.bmjpg.com 